\title{
Percent in White Blood Count Differential
}

National Cancer Institute

\section{Source}

National Cancer Institute. Percent in White Blood Count Differential. NCI Thesaurus. Code C67215.

A unit for percentage measurement of fraction of any type of white blood cells in the total white blood cell count differential. 